\title{
Energy and Environmental Retrofit of Existing School Buildings: Potentials and Limits in the Large-Scale Planning
}

\author{
Giuliano Dall'O' and Luca Sarto
}

\begin{abstract}
This chapter summarizes the results of research activities promoted by a group of researchers working in ABC Department-Politecnico di Milano aimed at energy and environmental requalification of school buildings located in the Lombardy region (Italy). The buildings subject to energy audits have been selected considering various factors, including the type of user (e.g. kindergartens, elementary schools, middle schools, etc.), construction period, construction technology and degradation. The methodological approach considers energy retrofit scenarios with different energy performance targets and required investments. The results of the research, which is concerned with a substantial and diversified existing building stock, provide public administrators decision-making tools and indicators supporting the energy and environmental retrofit actions for the existing schools. Although the potential for energy savings and reduced environmental impact is important in all scenarios, the achievement of very high energy performance targets is not always economically convenient and is sometimes technically impossible to reach. Large-scale energy planning, therefore, always requires in-depth energy audits that allow defining the optimal energy performance targets. The research activities demonstrate that it is convenient, when the energy performance of a building is improved, to consider also the environmental aspects. For some sample school buildings simulation analyses were carried out in accordance with the LEED $^{\circledR}$ protocol, and the higher cost due to environmental enhancement (e.g. the choice of ecological materials, the recycling of demolition materials or the use of renewable energy sources) is absolutely acceptable in the intervention economy.
\end{abstract}

Keywords Energy efficiency in school building - School buildings retrofit • Sustainability of school buildings $\cdot$ Green energy audit of buildings $\cdot$ LEED $^{\circledR}$ protocol

\footnotetext{
G. Dall'O' (ه)

Architecture, Built Environment and Construction Engineering-ABC Department,

Politecnico di Milano, Milan, Italy

e-mail: giuldal@polimi.it

L. Sarto

Milan, Italy

(C) The Author(s) 2020

S. Della Torre et al. (eds.), Buildings for Education, Research for Development, https://doi.org/10.1007/978-3-030-33687-5_28
} 


\section{Introduction}

Improving the energy and environmental performance of public buildings, particularly as regards schools, is important for the promotion of a culture of energy efficiency among the local population. Indeed, the European Union has developed strategies particularly for this sector using specific legislation. Article 5 of Directive 2012/27/EU of 25 October 2012 on energy efficiency requires Member States to ensure that, as from 1 January $2014,3 \%$ of the total floor area of central government-owned and -occupied, heated or cooled buildings is renovated each year to meet the minimum energy performance requirements that each Member State has set in application of Article 4 of the Energy Performance of Buildings Directive (2010/31/EU).

Nowadays, there are over 40,000 buildings in Italy for exclusive or prevalent school use - of which one-third is concentrated in ten provinces-with thermal consumption of 9.5 TWh/year and electricity consumption of 3.66 TWh/year. At the School Building Registry it appears that in $58 \%$ of school buildings, measures have already been implemented to save energy, installing photovoltaic panels, double glazing and double windows or isolating the external walls and roof (Dall'O' and Sarto 2013).

In this chapter the results of three researches promoted within the ABC Department of the Politecnico di Milano are reported. The first concerns a study of 49 school building complexes in the Lombardy region: through detailed energy audits, three different energy retrofit scenarios were evaluated.

The second research concerns a research extended to 49 high schools owned by the province of Milan (now Metropolitan City of Milan). The energy consumptions calculated with the actual energy consumption and savings estimates are made on three energetic retrofit scenarios.

The third research proposes and discusses a study which provides a considerable improvement in the environmental quality of 14 school buildings (pre-schools, primary and secondary) located in two municipalities in Milan Province, northern Italy.

\section{Energy Retrofit of Existing School Buildings: A Case Study for Schools up to Lower Secondary Schools}

For public authorities, improving the energy efficiency of public buildings is an important goal. Data from CESTEC, the energy register of the Lombardy region, concerning energy certificates in the Lombardy region show that $49.4 \%$ of school buildings are in class $\mathrm{G}$ (the worst efficiency class according to the classification scale); $13.4 \%$ are in class $\mathrm{F} ; 10.8 \%$ are in class $\mathrm{E} ; 11.6 \%$ are in class $\mathrm{D} ; 9.7 \%$ are in class $\mathrm{C} ; 3.3 \%$ are in class $\mathrm{B}$; and only $1.9 \%$ are in class $\mathrm{A}$ or $\mathrm{A}+$ (www.cestec.it 2019). 
On the other hand, to improve the energy performance of public buildings, and in particular school buildings, large investments are required by the Public Administration (PA). The economy over the next several years and the Stability Pact, which is now mandatory for the PA of Italy to reduce the public debt, will most likely limit direct investments.

As regard the performance quality, the energy retrofit of school buildings aims at high energy performance comparable to that of new buildings. The improvement in energy performance, however, has a specific cost, which increases exponentially the closer we get to the high energy classes. In order to make investments on energy retrofit cost-effective, it is useful to understand to what extent it is convenient to upgrade existing buildings. In other words, is it always economically convenient to push energy performance up to the highest level? The aim of this study was precisely this: to outline different scenarios and evaluate the economic convenience limits in energy retrofit investments (Dall'O' and Sarto 2013).

The study is based on data collected from an energy audit campaign. The energy analysis concerns school building complexes owned by 16 municipalities. The school building stock (49 school building complexes comprising 77 buildings) includes a large variety of building types (pre-schools 33\%, primary schools $18 \%$, secondary schools $12 \%$ and mixed schools $37 \%$ ). The energy performance of the buildings varies widely because of different building features related to the various construction periods.

The year of construction of the school building complexes ranges over a wide period, from 1920 to 2009: 9 complexes up to 1960, 7 complexes between 1961 and 1970, 25 complexes between 1971 and 1980, and 8 complexes built after 1981. The distribution of the construction years is related to the social needs, in terms of the number of children of school age in the period in question.

Figure 1 shows the comparison between the actual and calculated primary thermal energy consumption due to space heating of the school building stock. The dashed line represents the perfect match between the two values, while the regression line represents the average situation of the entire school building stock. The two regression lines are comparable, the measured energy consumption of all the buildings is $22 \%$ lower than the predicted consumption and this can be considered a good match. Thus the heating plant is switched off during night and this could achieve a reduction in energy consumption of more than $30 \%$ as stated in EN 13790 Standard (ISO 2008) as a function of inertia and other parameters which cannot be evaluated with the available data.

As regards to the energy retrofit actions, three scenarios were considered:

- In the standard scenario, the objective is to provide a technological upgrade of the heating plants with minimal investment;

- In the cost-effective scenario, the objective is to significantly increase the energy performance of the building envelope and the heating plants;

- In the high-performance scenario, the objective is to greatly increase the energy performance of the school building complexes up to the standards required by near-zero energy buildings (Art. 9 Directive 31/2010). 


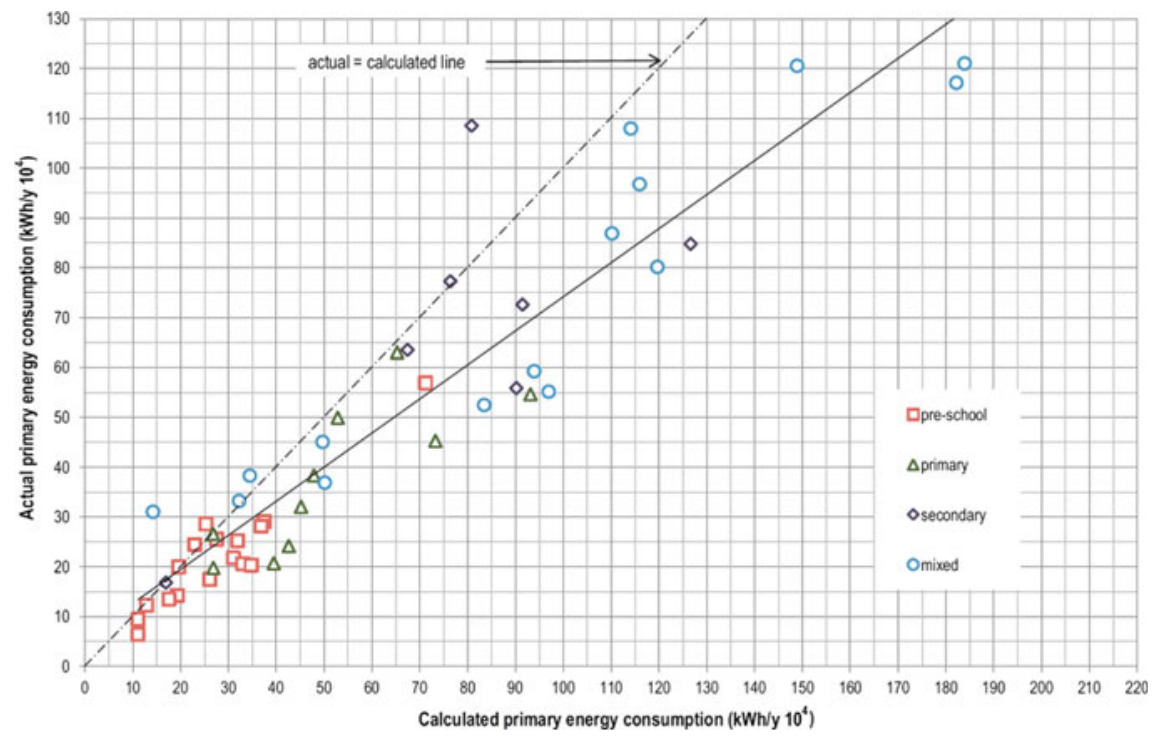

Fig. 1 Comparison between the actual and calculated primary thermal energy consumption due to space heating of the school buildings stock

In the standard scenario, the achievable energy savings are $15 \%$, with an investment, referred to the net floor area of the buildings, of $14.0 € / \mathrm{m}^{2}$ and a simple payback (SPB) of 5.7 years. This scenario represents a typical situation of low-profile maintenance actions.

In the cost-effective scenario, the energy retrofit measures are applied to all the school building complexes. Considering the entire building stock, the achievable energy savings are $67 \%$, with an investment required of $121.9 € / \mathrm{m}^{2}$ with a SPB of 13.4 years.

In the high-performance scenario, the energy retrofit measures are applied to all of the school building complexes with the objective of obtaining the maximum energy performance. This scenario does not consider cost effectiveness (i.e. a limitation of the SPB), but rather the technical and physical constraints due to the fact that we are acting on existing buildings, some of which are historical. For this reason it is not always possible to obtain the maximum projected energy performance and some building complexes do not reach the class A standard but a lower standard (e.g. class B or class C) according to the energy classification scheme of that time (2013).

Considering the entire building stock, the achievable energy saving is $81 \%$, with an investment required of $479.4 € / \mathrm{m}^{2}$ with a SPB of 42.4 years. Figure 2 shows the cost distribution of high-performance scenario.

This study demonstrates that reaching high levels of energy performance to comply with the EPBD recast could be very difficult or not cost-effective in many cases. Sometimes the cost of energy rehabilitation for the increasing of heating performance is comparable with the cost of a new building. 
Fig. 2 Cost distribution in scenario 3

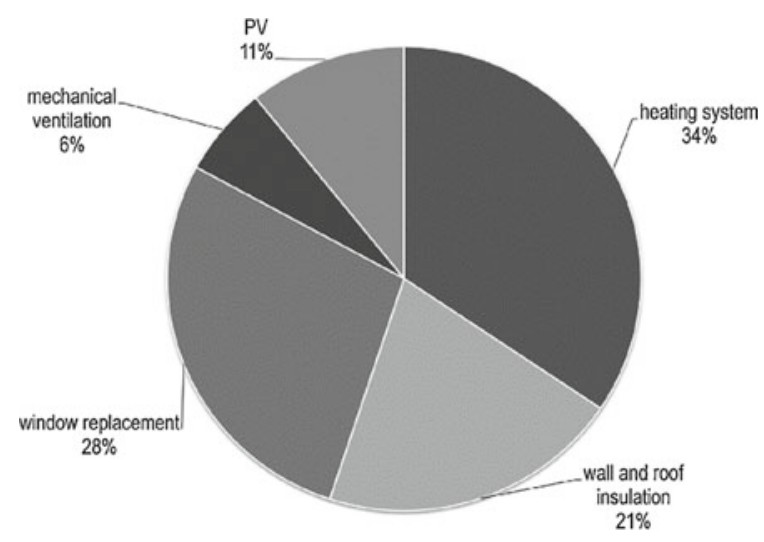

If the target is less ambitious (effective scenario), it is possible to reduce consistently energy consumption for space heating with a reasonable simple pay-back time, thereby reducing the environmental impact of school buildings.

\section{Energy Retrofit of Existing School Buildings: A Case Study for High Schools}

The case study presented in this section concerns a research which was carried out on an existing school building stock located in the Lombardy region in 2014. Unlike the case discussed in Sect. 3, in this case the school buildings, owned by the Province of Milan, concern upper secondary schools. It constists of 59 large school complexes with volumes ranging between $4,600 \mathrm{~m}^{3}$ and $164,860 \mathrm{~m}^{3}$ (average volume $45,545 \mathrm{~m}^{3}$ ).

For each school complex, a detailed energy audit was made in order:

- to define digital models of the buildings according to the ISO 13790 standard (ISO 2008);

- to compare the theoretical energy consumption with the actual energy consumption normalized with the standard day degrees;

- to calibrate the digital models;

- to define possible retrofit actions based on three scenarios.

Figure 3 shows the comparison between real normalized energy consumption and calculated theoretical consumption. From the graph it can be observed how the correlation is not high $\left(R^{2}=0.2715\right)$. Considering the set of cases, the analytical calculation overestimates real consumption by $53 \%$.

The differences that energize in individual cases, shown in Fig. 3, are due to several factors: 


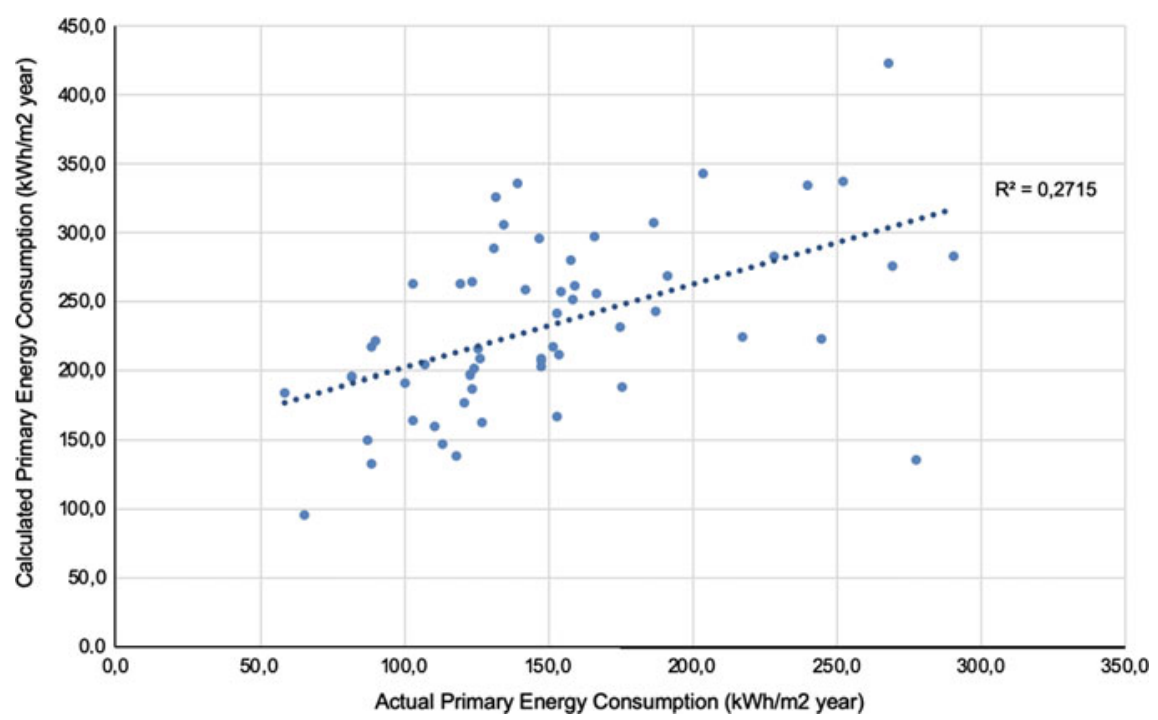

Fig. 3 Comparison between calculated and normalized actual primary energy consumption

- in the calculation we consider a standard internal temperature $\left(20{ }^{\circ} \mathrm{C}\right)$, often different from the real one;

- the periods of use of the spaces may be different from those declared;

- there are inefficiencies in the heating system regulation system.

Regarding the energy retrofit scenarios, the following choices were made:

- Scenario 1: minimum interventions aimed at restoring the complete operation of the plants;

- Scenario 2: interventions both on plants, with replacement of components and systems that are no longer efficient, and easy and low-cost interventions on the building envelope;

- Scenario 3: Heavy requalification of the building envelope (e.g. ETICSExternal Thermal Insulation Composite System and window replacement) and requalification of the plants.

In some cases not all the three scenarios were simulated because interventions were not needed or not applicable for architectural constrains.

Possible uses of renewable energy sources have not been taken into consideration.

Considering the entire building stock, starting from the specific consumption indicator weighted on the surfaces of $144 \mathrm{kWh} / \mathrm{m}^{2}$ per year (baseline), with Scenario 1 it reduces to $131 \mathrm{kWh} / \mathrm{m}^{2}$ per year; with Scenario 2 it reduces to $115 \mathrm{kWh} / \mathrm{m}^{2}$ per year; and with Scenario 3 it is reduced to $75 \mathrm{kWh} / \mathrm{m}^{2}$ per year.

The cost of Scenario 3, roughly equal to $1000 € / \mathrm{m}^{2}$ makes the application of energy retrofit actions not acceptable. 


\section{Increase in Environmental Sustainability in School Buildings: Case Studies}

This paragraph discusses a feasibility study which provides a considerable improvement in the environmental quality of 14 school buildings (pre-schools, primary and secondary) located in Cesano Boscone and Trezzano sul Naviglio, two municipalities in Milan province of northern Italy. The objective is to ensure the requirements for LEED ${ }^{\circledR}$ certification according to V2 version of the protocol (USGBC 2009).

For the school buildings the "Green Energy Audit" (GEA) procedure described in (Dall'O' et al. 2012; Dall'O' 2013) was applied, in order to verify the possible improvement of energy efficiency and environmental quality, in accordance with the LEED $^{\circledR}$ for schools rating system. The objective of the study was to ensure at least the minimum requirements for obtaining LEED ${ }^{\circledR}$ certification (Dall 'O' et al. 2013).

The aim of GEA is to evaluate the degree of improvement in sustainability of the building as a whole that can be obtained through the proposed choices; such choices do not necessarily generate an advantage in terms of energy saving, but they can generate many advantages as regard to sustainability. If the standard of comparison is the LEED ${ }^{\circledR}$ Protocol (USGBC 2009), then the problem is in understanding how the application of a certain retrofit action can help to meet the credits. GEA, therefore, integrates two strategic elements, energy saving and environmental impact reduction, by mixing the Energy Audit and LEED ${ }^{\circledR}$ methodologies.

This synergy strengthens the role of the classic energy audit by providing a method that not only optimizes the energy performance of existing buildings but also achieves a green retrofit of buildings.

Table 1 summarizes the main technical characteristics of the school buildings considered in the study, while Table 2 shows also the green house gases (GHG) reduction, assessed as total savings of each building, resulting from the implementation of all retrofit measures, and the energy saving for each building school calculated according to the prerequisite 2 of the LEED Protocol.

To obtain LEED ${ }^{\circledR}$ certification, the applicant projects must satisfy all the prerequisites and should be qualified for a number of points to attain the minimum established project ratings equal to 40 points (red line in Fig. 4).

Having satisfied the basic prerequisites of the program, the applicant projects are then rated according to their degree of compliance within the rating system: eight buildings fall within the level of Certified with an average score equal to 46.1, while the remaining six reach the Silver with an average score equal to 50.7. So our objective to achieve $\mathrm{LEED}^{\circledR}$ certification for all buildings while maximizing energy performance has been achieved. The study shows that there is a technical feasibility: the credits are between 42 and 54 (see Fig. 4).

The economic evaluation was conducted considering the costs of retrofits (hard cost) but also soft costs and the cost of Green Building Certification Institute (0.4\%).

Cost items considered in the economic evaluation concern: Building envelope retrofit cost, heating systems retrofit cost, ventilation systems cost, solar PV cost (for the installation of a polycrystalline PV system), Green Building Certification 
Table 1 Data of some characteristics of the buildings

\begin{tabular}{l|l|l|l|l|l|l|c}
\hline Bldg. & Type & Year & Occupants & $\begin{array}{l}\text { Net } \\
\text { surf. } \\
\left(\mathrm{m}^{2}\right)\end{array}$ & $\begin{array}{l}\text { Volume } \\
\left(\mathrm{m}^{3}\right)\end{array}$ & $\begin{array}{l}\text { Site } \\
\text { area } \\
\left(\mathrm{m}^{2}\right)\end{array}$ & $\begin{array}{l}\text { Bldg. } \\
\text { footprint } \\
\left(\mathrm{m}^{2}\right)\end{array}$ \\
\hline$\# 1$ & PS & $1965-1966$ & 260 & 2345 & 9920 & 5770 & 1521 \\
\hline$\# 2$ & SS & 1980 & 352 & 5190 & 31345 & 8144 & 2060 \\
\hline$\# 3$ & PS & 1976 & 303 & 3300 & 21504 & 18259 & 2696 \\
\hline$\# 4$ & PS & 1972 & 238 & 2805 & 11634 & 6339 & 1980 \\
\hline$\# 5$ & NS & 1974 & 180 & 1144 & 5468 & 5143 & 1266 \\
\hline$\# 6$ & PS-SS & 1974 & 617 & 6019 & 28808 & 12210 & 3302 \\
\hline$\# 7$ & NS & 1973 & 132 & 688 & 3045 & 14974 & 837 \\
\hline$\# 8$ & NS & 1976 & 185 & 1124 & 4248 & 4491 & 1190 \\
\hline$\# 10$ & NS & $1974-1984$ & 131 & 714 & 2598 & 5132 & 841 \\
\hline$\# 11$ & NS & 1973 & 137 & 1144 & 5468 & 4787 & 1265 \\
\hline$\# 12$ & NS & 1962 & 253 & 1833 & 8120 & 45608 & 13799 \\
\hline$\# 13$ & NS & 1968 & 146 & 876 & 3478 & 31246 & 11300 \\
\hline$\# 14$ & PS & $1966-1984$ & 137 & 773 & 2978 & 29555 & 9535 \\
\hline
\end{tabular}

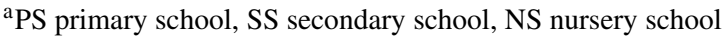

Table 2 Data for primary energy demand and percentage of primary energy savings

\begin{tabular}{l|l|l|l|l|l|l|l}
\hline Bldg. & $\begin{array}{l}\text { Primary } \\
\text { energy for } \\
\text { heating } \\
\text { and } \\
\text { ventilation } \\
\left(\mathrm{kWh} / \mathrm{m}^{3}\right. \\
\text { year) }\end{array}$ & $\begin{array}{l}\text { Primary } \\
\text { energy } \\
\text { for } \\
\text { domestic } \\
\text { hot water } \\
\left(\mathrm{kWh} / \mathrm{m}^{3}\right. \\
\text { year) }\end{array}$ & $\begin{array}{l}\text { Primary } \\
\text { energy } \\
\text { for } \\
\text { lighting } \\
\left(\mathrm{kWh} / \mathrm{m}^{3}\right. \\
\text { year })\end{array}$ & $\begin{array}{l}\text { Primary } \\
\text { energy } \\
\text { for } \\
\text { process } \\
\text { energy } \\
\left(\mathrm{kWh} / \mathrm{m}^{3}\right. \\
\text { year })\end{array}$ & $\begin{array}{l}\text { Primary } \\
\text { energy for } \\
\text { renewable } \\
\text { energy } \\
\left(\mathrm{kWh} / \mathrm{m}^{3}\right. \\
\text { year })\end{array}$ & $\begin{array}{l}\text { Emissions } \\
\text { savings } \\
\left(\mathrm{tCO}_{2}\right)\end{array}$ & $\begin{array}{l}\text { Percentage } \\
\text { of primary } \\
\text { energy } \\
\text { savings } \\
(\%)\end{array}$ \\
\hline$\# 1$ & 5.65 & 0.27 & 2.58 & 8.32 & 3.36 & 52.64 & 67.6 \\
\hline$\# 2$ & 5.71 & 0.12 & 1.80 & 6.35 & 3.32 & 140.89 & 66.4 \\
\hline$\# 3$ & 6.77 & 0.15 & 1.67 & 6.44 & 3.62 & 79.51 & 64.6 \\
\hline$\# 4$ & 6.73 & 0.21 & 2.63 & 9.19 & 5.87 & 67.51 & 72.0 \\
\hline$\# 5$ & 7.92 & 0.34 & 2.28 & 8.66 & 2.90 & 28.90 & 62.4 \\
\hline$\# 6$ & 5.81 & 0.55 & 2.63 & 8.88 & 3.11 & 163.29 & 66.8 \\
\hline$\# 8$ & 9.57 & 0.45 & 2.46 & 8.54 & 6.73 & 14.20 & 66.5 \\
\hline$\# 9$ & 12.96 & 0.52 & 3.00 & 11.71 & 11.47 & 16.85 & 71.4 \\
\hline$\# 10$ & 9.91 & 0.26 & 2.28 & 7.20 & 6.81 & 19.50 & 64.3 \\
\hline$\# 11$ & 10.65 & 0.23 & 3.60 & 10.61 & 4.54 & 48.22 & 61.3 \\
\hline$\# 12$ & 10.68 & 0.44 & 1.95 & 10.94 & 10.13 & 22.73 & 74.6 \\
\hline$\# 13$ & 10.97 & 0.48 & 3.29 & 11.55 & 7.27 & 19,89 & 67.1 \\
\hline & 8.38 & 0.20 & 2.30 & 9.62 & 6.33 & 75.10 & 70.5 \\
\hline
\end{tabular}




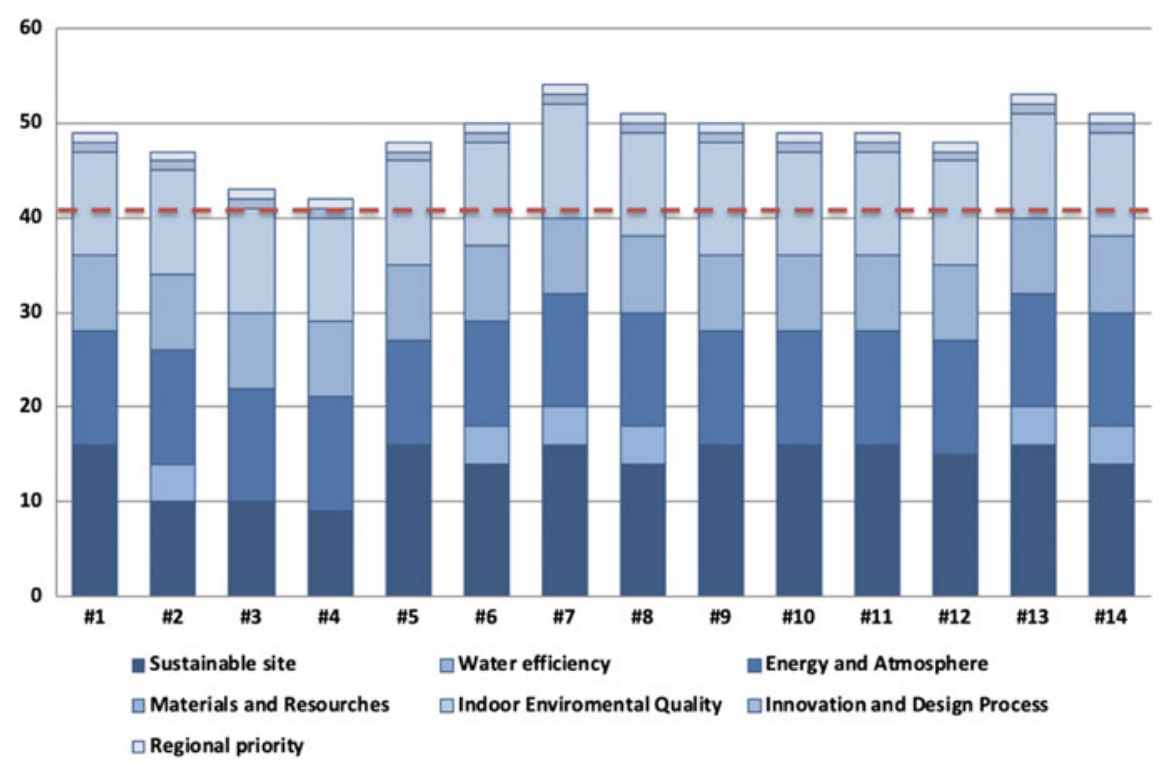

Fig. 4 Potential to improve sustainability of school buildings

Institute cost (related to LEED $^{\circledR}$ certification), soft cost (related to building design that meets LEED $^{\circledR}$ standards), increased renovation cost (related to higher cost of renovation to satisfy $\mathrm{LEED}^{\circledR}$ standards), water efficiency cost (related to installing water flow reducers and double flow toilets).

The cost of building envelope retrofit is the highest cost item with $53.2 \%$ of the total cost; heating systems retrofit is the second largest cost item with $29.7 \%$ of the total cost (the cost of building envelope and heating systems retrofit is therefore $82.9 \%$ of the total cost).

The economic issue remains, however, and is even greater when operating inside the public market, which is made up of public buildings such as schools.

The following question arises: should in the sector of public building retrofit strategies should be limited to an improvement of the energy performance or should aim to improve the sustainability as well? The purpose of this study was also to give a response to this question. Considering the feedback emerging from our research, which is based on concrete examples of school buildings subjected to green energy audit, we can state that it is a more appropriate aim to improve the sustainability.

Given that the increased spending is due to the portion of energy retrofits, when a building is under redevelopment we should look beyond. It is time to orientate strategies toward sustainability targets. This choice is particularly important for the school buildings for a better comfort and with a higher indoor air quality contributing to improve the conditions for learning. 


\section{Conclusions}

The research presented and discussed in this chapter highlights a great interest in dealing with the issue of energy retrofit of school buildings. In assessing the opportunities for reducing energy requirements, however, the economic aspects that often constrain actions must be considered.

In the first and second case study discussed we can easily confirm that, while it is very important to upgrade existing school buildings, it is not always convenient to push energy performance beyond certain values. The technical and economic constraints encountered in practice when intervening on existing buildings often make it convenient to replace existing buildings with new buildings. The third case study highlights the opportunity to approach the energy redevelopment of buildings also considering the environmental aspects.

\section{References}

Dall'O' G, Speccher A, Bruni E (2012) The green energy audit, a new procedure for the sustainable auditing of existing buildings integrated with the LEED Protocols. Sustain Cities Soc 2012(3):5465

Dall'O G (2013) Green energy audit versus LEED® protocols. In: Green energy audit of buildings, a guide for sustainable energy audit of buildings, 1st edn, Chapter 9, pp. 213-240. Springer, London

Dall'O' G, Bruni E, Panza A (2013) Improvement of the sustainability of existing school buildings according to the leadership in energy and environmental design (LEED)® Protocol: a case study in Italy. Energies 6:6487-6507. https://doi.org/10.3390/en6126487

Dall'O' G, Sarto L (2013) Potential and limits to improve energy efficiency in space heating in existing school buildings in northern Italy. Energy Build 2013(67):298-308

International Organization for Standardization (ISO) (2008) ISO 13790: 2008- Energy performance of buildings - calculation of energy use for space heating and cooling

United States Green Building Council (USGBC) (2009) LEED reference guide for green building design and construction. USGBC, Washington, WA, USA, ISBN: 9781932444346

Open Access This chapter is licensed under the terms of the Creative Commons Attribution 4.0 International License (http://creativecommons.org/licenses/by/4.0/), which permits use, sharing, adaptation, distribution and reproduction in any medium or format, as long as you give appropriate credit to the original author(s) and the source, provide a link to the Creative Commons license and indicate if changes were made.

The images or other third party material in this chapter are included in the chapter's Creative Commons license, unless indicated otherwise in a credit line to the material. If material is not included in the chapter's Creative Commons license and your intended use is not permitted by statutory regulation or exceeds the permitted use, you will need to obtain permission directly from the copyright holder. 